\title{
Growth of $\mathrm{Gd}_{2} \mathrm{O}_{3}$ nanoparticles inside mesoporous silica frameworks
}

Mohamed A. Ballem, Fredrik Söderlind, Per Nordblad, Per-Olov Käll and Magnus Odén

\section{Linköping University Post Print}

N.B.: When citing this work, cite the original article.

Original Publication:

Mohamed A. Ballem, Fredrik Söderlind, Per Nordblad, Per-Olov Käll and Magnus Odén, Growth of $\mathrm{Gd}_{2} \mathrm{O}_{3}$; nanoparticles inside mesoporous silica frameworks, 2013, Microporous and Mesoporous Materials, (168), 221-224.

http://dx.doi.org/10.1016/j.micromeso.2012.10.009

Copyright: Elsevier

http://www.elsevier.com/

Postprint available at: Linköping University Electronic Press

http://urn.kb.se/resolve?urn=urn:nbn:se:liu:diva-67918 


\title{
Growth of $\mathrm{Gd}_{2} \mathrm{O}_{3}$ nanoparticles inside mesoporous silica frameworks
}

Mohamed Ali Ballem ${ }^{\mathrm{a}}$, Fredrik Söderlind ${ }^{\mathrm{a}, *}$, Per Nordblad ${ }^{\mathrm{b}}$, Per-Olov Käll ${ }^{\mathrm{c}}$, Magnus Odén $^{\mathrm{a}}$

${ }^{a}$ Division of Nanostructured Materials, Department of Physics, Chemistry and Biology, Linköping University, 58183 Linköping, Sweden

${ }^{b}$ Department of Engineering Sciences, Uppsala University, Box 534, SE-751 21 Uppsala, Sweden

${ }^{c}$ Division of Chemistry, Department of Physics, Chemistry and Biology, Linköping University, 58183 Linköping, Sweden

*Corresponding author: Tel.: +46(0)13 28 1780; fax: +46(0)13 13 7568. E-mail address: freso@ifm.liu.se (F. Söderlind)

\begin{abstract}
Gadolinium oxide $\left(\mathrm{Gd}_{2} \mathrm{O}_{3}\right)$ nanoparticles with very small size and narrow size distribution were synthesized by infiltration of $\mathrm{Gd}\left(\mathrm{NO}_{3}\right)_{3} \cdot 6 \mathrm{H}_{2} \mathrm{O}$ as an oxide precursor into the pores of SBA-15 mesoporous silica using a wet-impregnation technique. High resolution transmission electron microscopy and X-ray diffraction show that during the hydrothermal treatment of the precursor at $550{ }^{\circ} \mathrm{C}$, gadolinium oxide nanoparticles inside the silica pores are formed. Subsequent dissolution of the silica framework in aqueous $\mathrm{NaOH}$ resulted in well dispersed nanoparticles with an average diameter of $3.6 \pm 0.9 \mathrm{~nm}$. If $\mathrm{GdCl}_{3} \cdot 6 \mathrm{H}_{2} \mathrm{O}$ is used as precursor, $\mathrm{GdOCl}$ is formed instead of $\mathrm{Gd}_{2} \mathrm{O}_{3}$. The $\mathrm{Gd}_{2} \mathrm{O}_{3}$ nanoparticles showed a weak antiferromagnetic behaviour, as expected.
\end{abstract}

Keywords: $\mathrm{Gd}_{2} \mathrm{O}_{3}$; Nanoparticles; Nanocasting; Mesoporous silica; SBA-15 


\section{Introduction}

Synthesis of metal oxides nanoparticles with well-defined shapes and sizes, has received considerable attention due to the potential applications of such particles in many different areas such as catalysis, sensors, batteries, and solar cells [1,2]. Several of the rare earth elements and their corresponding oxides are of exceedingly technical importance and are used in critical parts in, e.g., electronic, magnetic, nuclear, optical, and catalytic devices $[3,4]$. Gadolinium oxide, one of the rare earth oxides, is used as an additive in other ceramics, e.g., $\mathrm{Gd}_{2} \mathrm{O}_{3}$ was used to stabilize the tetragonal phase of zirconia [5] and to improve the densification of sintered $\mathrm{SiC}$ [6]. At present, attempts are being made to use strongly paramagnetic $\mathrm{Gd}_{2} \mathrm{O}_{3}$ nanoparticles for contrast enhancement in magnetic resonance imaging (MRI) [7] and, most recently, Faucher et al. [8] reported on the possibility of using ultra-small gadolinium oxide nanoparticles to image brain cancer cells in vivo by MRI.

Several methods have been reported on the synthesis of nanosized $\mathrm{Gd}_{2} \mathrm{O}_{3}$, e.g. colloidal and combustion methods $[9,10]$, Chang et al. [11] reported on the preparation of a mesoporous $\mathrm{Gd}_{2} \mathrm{O}_{3}$ network with a tubular nanostructure by using a combination of soft template and sol-gel methods. In general, liquid based synthesis methods usually require careful control of reaction parameters such as $\mathrm{pH}$, temperature, and concentration of reactants in order to obtain the desired particle size and morphology. Thus, it remains a challenge to develop a simple route to synthesize $\mathrm{Gd}_{2} \mathrm{O}_{3}$ nanoparticles with controlled size and shape in aqueous media.

In this work, we have extended a route previously reported by Ballem et al. [12,13] in the synthesis of $\mathrm{ZrO}_{2}$ and $\alpha-\mathrm{Fe}_{2} \mathrm{O}_{3}$ (hematite) nanoparticles, by using mesoporous silica as a template to obtain monodispersed $\mathrm{Gd}_{2} \mathrm{O}_{3}$ nanoparticles by means of impregnation of a 
suitable precursor into the pores of SBA-15 silica, and during the hydrothermal treatment the precursor is decomposed into the desired product. The resulting $\mathrm{Gd}_{2} \mathrm{O}_{3}$ nanoparticles are crystalline and have a narrow size distribution which makes them promising candidates in some of the above mentioned applications. 


\section{Experimental}

\subsection{Materials}

Triblock copolymer Pluronic P123 $\left(\mathrm{HO}\left(\mathrm{CH}_{2} \mathrm{CH}_{2} \mathrm{O}\right)_{20}\left(\mathrm{CH}_{2} \mathrm{CH}\left(\mathrm{CH}_{3}\right) \mathrm{O}\right)_{70}\left(\mathrm{CH}_{2} \mathrm{CH}_{2} \mathrm{O}\right)_{20} \mathrm{H}\right.$, Aldrich), tetraethyl orthosilicate (Si(OEt) 4 , TEOS, $98 \%$, Aldrich), hydrochloric acid (HCl, $\geq 37 \%$, Fluka, ACS Reagent), gadolinium(III)nitrate hexahydrate $\left(\mathrm{Gd}\left(\mathrm{NO}_{3}\right)_{3} \cdot 6 \mathrm{H}_{2} \mathrm{O}\right.$, 99.9\% trace metals basis, Aldrich), and sodium hydroxide pellets $(\mathrm{NaOH}, \geq 97 \%$, Fluka), were used as received.

\subsection{Synthesis}

Mesoporous silica material SBA-15 was synthesized and used as template for confined growth of $\mathrm{Gd}_{2} \mathrm{O}_{3}$ nanoparticles. The detailed description of the synthesis route was reported by Sayari et al. [14], where P123 is used as a structure-directing agent and TEOS as the silica source in an aqueous solution of $\mathrm{HCl}$. For the infiltration step, a $0.01 \mathrm{M}$ solution of gadolinium nitrate was prepared by dissolving $0.45 \mathrm{~g}$ of $\mathrm{Gd}\left(\mathrm{NO}_{3}\right)_{3} \cdot 6 \mathrm{H}_{2} \mathrm{O}$ in $100 \mathrm{ml}$ water under mild stirring for $30 \mathrm{~min}$. About $15 \mathrm{ml}$ of the solution was added to a test tube containing $50 \mathrm{mg}$ of SBA-15 silica. The mixture was sonicated at $55^{\circ} \mathrm{C}$ for $4 \mathrm{~h}$, and the excess precursor solution was removed by centrifugation. The collected sample was dried at $100{ }^{\circ} \mathrm{C}$ for $\sim 20 \mathrm{~h}$ and was subsequently placed in a ceramic crucible and annealed in a muffle furnace. The furnace was heated at rate of $1{ }^{\circ} \mathrm{C} / \mathrm{min}$ up to $550{ }^{\circ} \mathrm{C}$ and was held at that temperature for $5 \mathrm{~h}$.

To remove the silica template an aqueous solution of $\mathrm{NaOH}(0.5 \mathrm{M})$ was mixed with the sample and sonicated at $55{ }^{\circ} \mathrm{C}$ for $5 \mathrm{~h}$, and the as-synthesized sample was subsequently collected as a powder by centrifugation (4000 rpm/10 min). 


\subsection{Characterization}

The crystalline structure of prepared materials was determined by powder X-ray diffractometry (Philips PW 1729) using CuKa radiation $(\lambda=1.5418 \AA$ ). Transmission electron microscopy (TEM) was performed with a FEI Tecnai $\mathrm{G}^{2}$ Microscope, operated at $200 \mathrm{kV}$. Energy dispersive X-ray spectroscopy (EDS) was performed in the TEM. Before examination in TEM, the sample was dispersed in acetone and deposited onto a copper grid and allowed to dry before the analysis.

Nitrogen adsorption-desorption measurements were performed at $77 \mathrm{~K}$ using a Micromeritics ASAP 2020 surface area and porosity analyzer. The samples were degassed at $473 \mathrm{~K}$ for $9 \mathrm{~h}$ before measurement. The specific surface area was determined by the Brunauer-Emmett-Teller (BET) model [15] over the relative pressure $\left(P / P_{0}\right)$ range of 0.08 -0.2 , the pore size distribution was derived from the adsorption isotherm branch using the Kruk-Jaroniec-Sayari (KJS) method [16]. Finally, the total pore volume was calculated from the amount of adsorbed $\mathrm{N}_{2}$ at $P / P_{0}=0.975$, and the micropore volume was determined using the $t$-plot method at a fitted thickness range of $0.35-0.50 \mathrm{~nm}$.

Thermogravimetric analysis was performed in a Netzsch STA 449C Jupiter instrument. About $18 \mathrm{mg}$ of the sample was placed in an $\mathrm{Al}_{2} \mathrm{O}_{3}$ crucible and heated to 600 ${ }^{\circ} \mathrm{C}$ at a rate of $10{ }^{\circ} \mathrm{C} / \mathrm{min}$. In situ gas analysis was performed using a Netzsch QMS 403C Aëolos mass spectrometer which was connected to the TG apparatus through a heated transfer capillary.

Magnetic measurements were performed in a Quantum Design MPMS SQUID magnetometer in the temperature range $5-60 \mathrm{~K}$, using a magnetic field strength of 1000 Oe. 


\section{Results and discussion}

Monodispersed mesoporous silica SBA-15 particles have been used as template for confined growth of gadolinium oxide nanoparticles. The overall morphology and the pore structure of the template are shown in the TEM micrograph in Figure 1. The rod-like particles have a diameter of $0.4-0.5 \mu \mathrm{m}$ and a length of about $1 \mu \mathrm{m}$. Hexagonally ordered cylindrical mesopores with a diameter of $10 \mathrm{~nm}$ are running along the longitudinal direction of the particles (see inset in Fig. 1).

The X-ray diffractogram of the SBA-15 silica impregnated with $\operatorname{Gd}\left(\mathrm{NO}_{3}\right)_{3}$ after annealing at $550{ }^{\circ} \mathrm{C}$ is presented in Figure 2a. All peaks can be assigned to cubic $\mathrm{Gd}_{2} \mathrm{O}_{3}$ (s. g. Ia 3 , No. 206) [17], suggesting that the impregnated precursor transformed to a large degree to the aimed at oxide. The broadening of the diffraction peaks is due to the small crystallite size of the formed nanoparticles, which are less than $10 \mathrm{~nm}$ as indicated by the TEM micrograph represented in Figure 2b. It is clear from this image that the pores of the silica template are occupied by the nanoparticles (see arrows), and the structure of the porous framework remains intact after the formation of the nanoparticles.

The pores of the silica are acting as hard template controlling the size of the growing nanoparticles. The effect was confirmed by repeating the same synthesis route with the mesoporous silica replaced by amorphous silica. The obtained product is shown in the micrograph in Figure 3a. The flake-shaped particles are highly crystalline, as shown by the HRTEM inset, and the X-ray diffractogram (Figure 3b), where all strong peaks can be assigned to the cubic $\mathrm{Gd}_{2} \mathrm{O}_{3}$ phase [17]. The result shows that, in the absence of the porous 
template, the gadolinium oxide crystals will grow much larger exhibiting a more or less unrestrained distribution of sizes and shapes, thus evidencing the size controlling role of the mesoporous silica template.

The details of the formation mechanism of $\mathrm{Gd}_{2} \mathrm{O}_{3}$ nanoparticles in the mesoporous silica channels are not known, but possibly it occurs via an initial formation of $\mathrm{Gd}(\mathrm{OH})_{3}$ at sufficiently high $\mathrm{pH}$. Upon the subsequent annealing step, the gadolinium hydroxide decomposes into the oxide. The TG-MS analysis of the impregnated SBA-15 shows an initial weight loss attributable only to $\mathrm{H}_{2} \mathrm{O}$, while at somewhat higher temperatures (270$450{ }^{\circ} \mathrm{C}$ ), nitrogen oxides ( $\mathrm{NO}$ and $\mathrm{NO}_{2}$ ) from the decomposing nitrate are observed along with stronger bounded water molecules (Fig. 4). An interesting observation is that if $\mathrm{GdCl}_{3} \cdot 6 \mathrm{H}_{2} \mathrm{O}$ is used as precursor instead of $\mathrm{Gd}\left(\mathrm{NO}_{3}\right)_{3} \cdot 6 \mathrm{H}_{2} \mathrm{O}$, the stable oxychloride $\mathrm{GdOCl}$ is formed rather than the pure oxide. To decompose lanthanide chlorides higher temperatures are usually needed than for the decomposition of lanthanide nitrates, probably due to the formation of the intermediate oxychloride compound [18].

$\mathrm{N}_{2}$ adsorption-desorption isotherms, and pore size distributions of the silica template before and after loading with $\mathrm{Gd}_{2} \mathrm{O}_{3}$, are shown in Figure 5, and physisorption data are listed in Table I. Both isotherms (Figure 5a) are of type IV, exhibiting H1 hysteresis loops and the effective pore diameter of the SBA-15 silica after incorporation of the $\mathrm{Gd}_{2} \mathrm{O}_{3}$ nanoparticles into the pores was measured to $9.51 \mathrm{~nm}$ (Figure $5 \mathrm{~b}$ and Table I). A significant decrease in the BET surface area, total pore volume, and the micropore volume (Table I), are a complementary evidence of pores being occupied by $\mathrm{Gd}_{2} \mathrm{O}_{3}$ nanoparticles. 
The TEM micrograph in Figure 6a shows the nanoparticles obtained after dissolution of the silica template in $0.5 \mathrm{M} \mathrm{NaOH}$. The nanoparticles are spherical and without agglomerations. The inset in Figure 6a is a high resolution TEM image of a single $\mathrm{Gd}_{2} \mathrm{O}_{3}$ nanoparticle. An indexed selected area electron diffraction pattern of the nanoparticles is shown in Figure $6 b$, exhibiting the expected reflections for cubic $\operatorname{Gd}_{2} \mathrm{O}_{3}$. The average particle size was determined by image analysis of TEM micrographs by measuring the diameter of about 240 particles using the DigitalMicrograph ${ }^{\mathrm{TM}} 3.9 .3$ software for GMS 1.4.3 (Gatan Software Team). The result is shown in the histogram in Figure 6c. From the fit of a Gaussian function to the histogram, the average diameter of the particles was determined to $3.6 \pm 0.9 \mathrm{~nm}$. The size distribution is narrow, and the sizes of the obtained nanoparticles appear small enough to be considered for in vivo MRI applications [19].

The magnetic properties were measured with the silica matrix removed, and shows a weak antiferromagnetic behavior with the Weiss constant $\theta=-2.40 \pm 0.02 \mathrm{~K}$ (Fig. 7). This magnitude of $\theta$ is much smaller than those reported for bulk materials which show values around $-17 \mathrm{~K}$ [20]. However, it has been recently reported that for small $\mathrm{Gd}_{2} \mathrm{O}_{3}$ nanocrystals $\theta$ values in the range -3 and $0 \mathrm{~K}$ were observed [21,22]. The magnetic moment of 5.8 $\mathrm{BM}$ is lower than the theoretical value of $7.94 \mathrm{BM}$, which could be due to traces of silica still remaining in the sample (c.f. supporting information Fig. S1). 


\section{Conclusion}

A simple route to synthesize small spherical $\mathrm{Gd}_{2} \mathrm{O}_{3}$ nanoparticles with a narrow size distribution $(3.6 \pm 0.9 \mathrm{~nm})$ has been demonstrated. The synthesis is based on the infiltration of a gadolinium nitrate solution into the pores of SBA-15 silica, where the mesoporous framework acts as a hard template for the growth of the nanoparticles. Successful removal of the silica template by aqueous sodium hydroxide resulted in monodispersed gadolinium oxide nanoparticles. The $\mathrm{Gd}_{2} \mathrm{O}_{3}$ nanocrystals show a weak antiferromagnetic behavior $(\theta \approx-2.4 \mathrm{~K})$, in good agreement with previous studies. 


\section{References}

[1] W. Beek, M. Wienk, R. Janssen, Adv. Mater. 16 (2004) 1009-1013.

[2] G. Oskam, J. Sol-Gel Sci. Tech. 37 (2006) 161-164.

[3] T. Tsuzuki, E. Pirault, P.G. McCormick, Nanostruct. Mater. 11 (1999) 125-131.

[4] S. Colussi, C. de Leitenburg, G. Dolcetti, A. Trovarelli, J. Alloy. Compd. 374 (2004) 387-392.

[5] S. Bhattacharyya, D.C. Agrawal, J. Mater. Sci. 30 (1995) 1495-1499.

[6] Z. Chen, J. Am. Ceram. Soc. 79 (1996) 530-532.

[7] A. Klasson, M. Ahrén, E. Hellqvist, F. Söderlind, A. Rosén, P.O. Käll, K. Uvdal, M. Engström, Contrast Media Mol. Imaging 3 (2008) 106-111.

[8] L. Faucher, A.A. Guay-Bégin, J. Lagueux, M.F. Côté, É. Petitclerc, M.A. Fortin, Contrast Media Mol. Imaging 6 (2011) 209-218.

[9] R. Bazzi, M.A. Flores-Gonzalez, C. Louis, K. Lebbou, C. Dujardin, A. Brenier, W. Zhang, O. Tillement, E. Bernstein, P. Perriat, J. Lumin. 102 (2003) 445-450.

[10] F. Söderlind, H. Pedersen, R.M. Petoral Jr, P.O. Käll, K. Uvdal, J. Colloid Interface Sci. 288 (2005) 140-148.

[11] Y.P. Chang, K.H. Liu, C.S. Chao, S.Y. Chen, D.M. Liu, Acta Biomater. 6 (2010) 3713-3719.

[12] M. Ballem, J. Córdoba, M. Odén, J. Nanopart. Res.13 (2011) 2743-2748.

[13] M.A. Ballem, X. Zhang, E.M. Johansson, J.M. Córdoba, M. Odén, Powder Technol. 217 (2012) 269-273.

[14] A. Sayari, B.H. Han, Y. Yang, J. Am. Chem. Soc. 126 (2004) 14348-14349.

[15] S. Brunauer, P.H. Emmett, E. Teller, J. Am. Chem. Soc. 60 (1938) 309-319.

[16] M. Kruk, M. Jaroniec, A. Sayari, Langmuir 13 (1997) 6267-6273.

[17] Powder Diffraction File (JCPDS 01-076-8040, International Center for Diffraction

Data, Swarthmore, PA, 1992).

[18] L. Eyring, Synthesis of Lanthanide and Actinide Compounds. Kluwer Academic Publishers: Dordrecht, 1991.

[19] A.C. Faure, S. Dufort, V. Josserand, P. Perriat, J.L. Coll, S. Roux, O. Tillement, Small 5 (2009) 2565-2575.

[20] A.E. Miller, F.J. Jelinek, K.A. Gschneidner Jr, B.C. Gerstein, J. Chem. Phys. 55 (1971) 2647-2648.

[21] H. Gustafsson, M. Ahrén, F. Söderlind, J.M. Córdoba Gallego, P.O. Käll, P.

Nordblad, P.O. Westlund, K. Uvdal, M. Engström, J. Phys. Chem. C 115 (2011) 54695477.

[22] M.A. Fortin, R.M. Petoral, F. Söderlind, A. Klasson, M. Engström, T. Veres, P.O. Käll, K. Uvdal, Nanotechnology 18 (2007) 395501. 
Table 1. Nitrogen physisorption data of the SBA-15 silica template before and after infiltration

\begin{tabular}{lcccc}
\hline \multicolumn{1}{c}{ Sample } & $\begin{array}{c}S_{B E T} \\
{\left[\mathrm{~m}^{2} / \mathrm{g}\right]}\end{array}$ & $\begin{array}{c}V_{t} \\
{\left[\mathrm{~cm}^{3} / \mathrm{g}\right]}\end{array}$ & $\begin{array}{c}V_{\mathrm{m}} \\
{\left[\mathrm{cm}^{3} / \mathrm{g}\right]}\end{array}$ & $\begin{array}{c}D_{p} \\
{[\mathrm{~nm}]}\end{array}$ \\
\hline SBA-15 template before impregnation & 893 & 1.17 & 0.05 & 9.65 \\
SBA-15 template after impregnation & 386 & 0.36 & 0.01 & 9.51
\end{tabular}

$S_{B E T}=$ BET surface area; $V_{\mathrm{t}}=$ total pore volume calculated at $P / P_{0}=0.975 ; V_{\mathrm{m}}=$ micropore volume calculated using the $t$-plot method; $D_{p}=$ mesopore diameter calculated from the adsorption isotherm branch, using the KJS method.

Fig. 1. TEM micrographs of the mesoporous silica template (SBA-15). The inset represents the pore structure.

Fig. 2. (a) XRD pattern of SBA-15 silica after impregnation with the $\mathrm{Gd}_{2} \mathrm{O}_{3}$ precursor and thermal treatment at $550{ }^{\circ} \mathrm{C}$. (b) A TEM micrograph showing that the pore structure of SBA-15 is left intact in the formation of the $\mathrm{Gd}_{2} \mathrm{O}_{3}$ nanoparticles.

Fig. 3. (a) TEM micrograph of $\mathrm{Gd}_{2} \mathrm{O}_{3}$ particles with flake morphology, synthesized using non-porous silica. The inset is the HRTEM image of the selected area at the edge of the flake. (b) The powder XRD pattern of the sample.

Fig. 4. The thermogravimetric analysis curve of SBA-15 impregnated with $\mathrm{Gd}\left(\mathrm{NO}_{3}\right)_{3}$.

Fig. 5. (a) Nitrogen adsorption-desorption isotherms for SBA-15 silica before (०), and after $(\bullet)$ impregnation, and (b) the corresponding pore size distributions.

Fig. 6. (a) TEM micrograph of $\mathrm{Gd}_{2} \mathrm{O}_{3}$ nanoparticles after dissolution of the SBA-15 template. The inset is an HRTEM image of a single nanoparticle. (b) The SAED of the 
corresponding nanoparticles. (c) The particle size distribution histogram with a Gaussian fit (solid line).

Fig. 7. The magnetization (M) and reciprocal susceptibility $\left(\chi^{-1}\right)$ vs $T$ curves $(H=1000$ Oe) for the $\mathrm{Gd}_{2} \mathrm{O}_{3}$ nanoparticles after dissolution of the SBA-15 template.

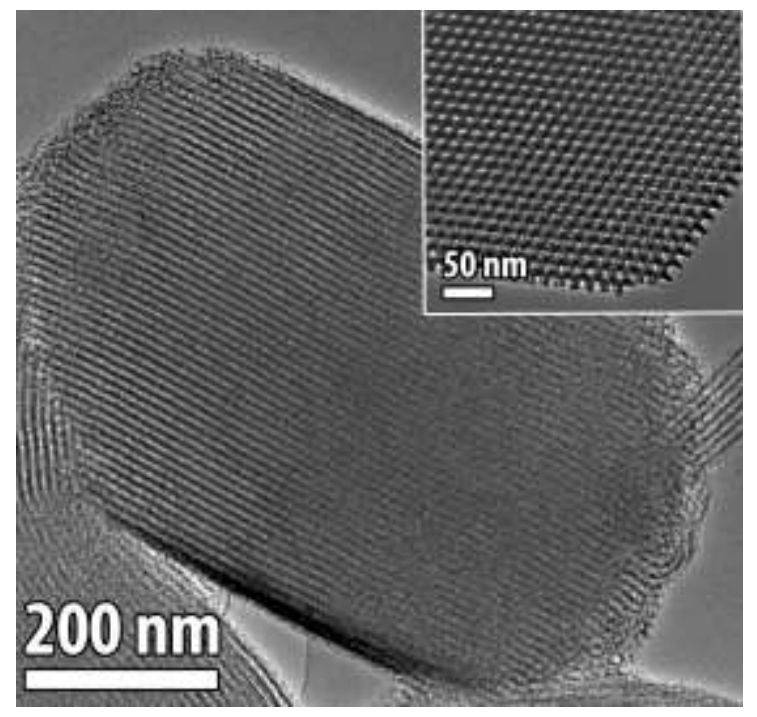

Fig. 1. 

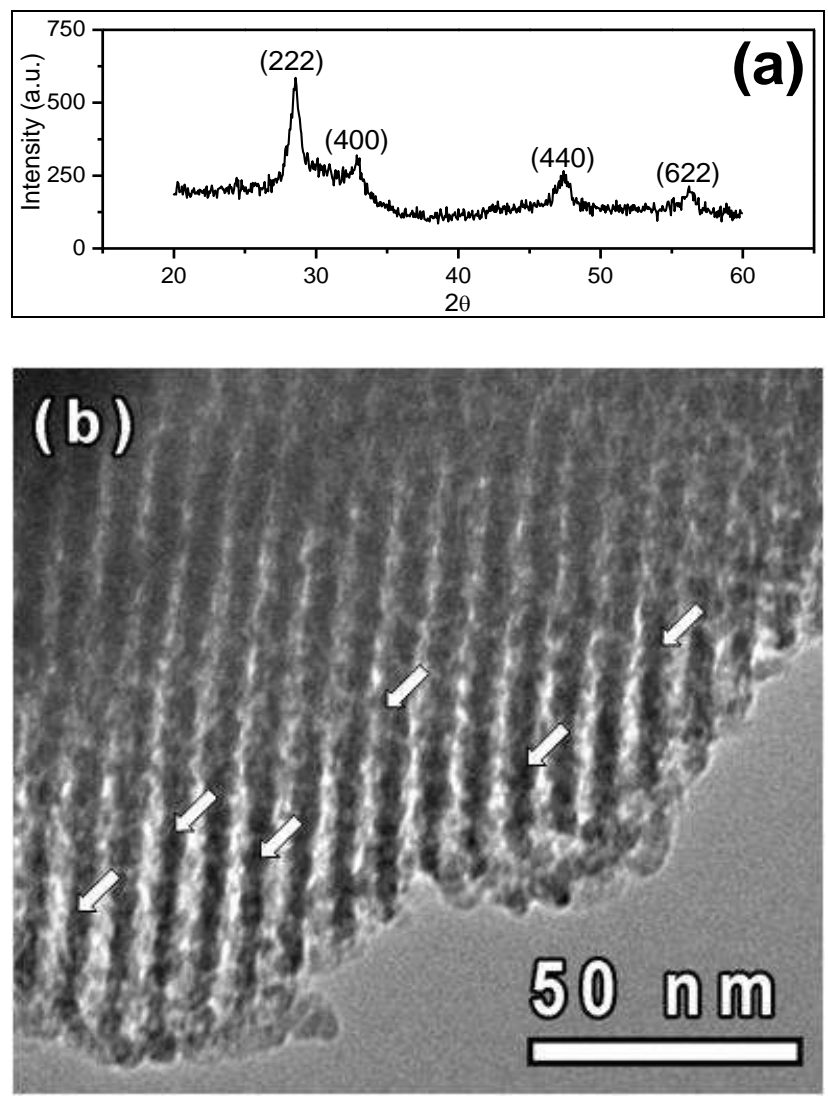

Fig. 2.
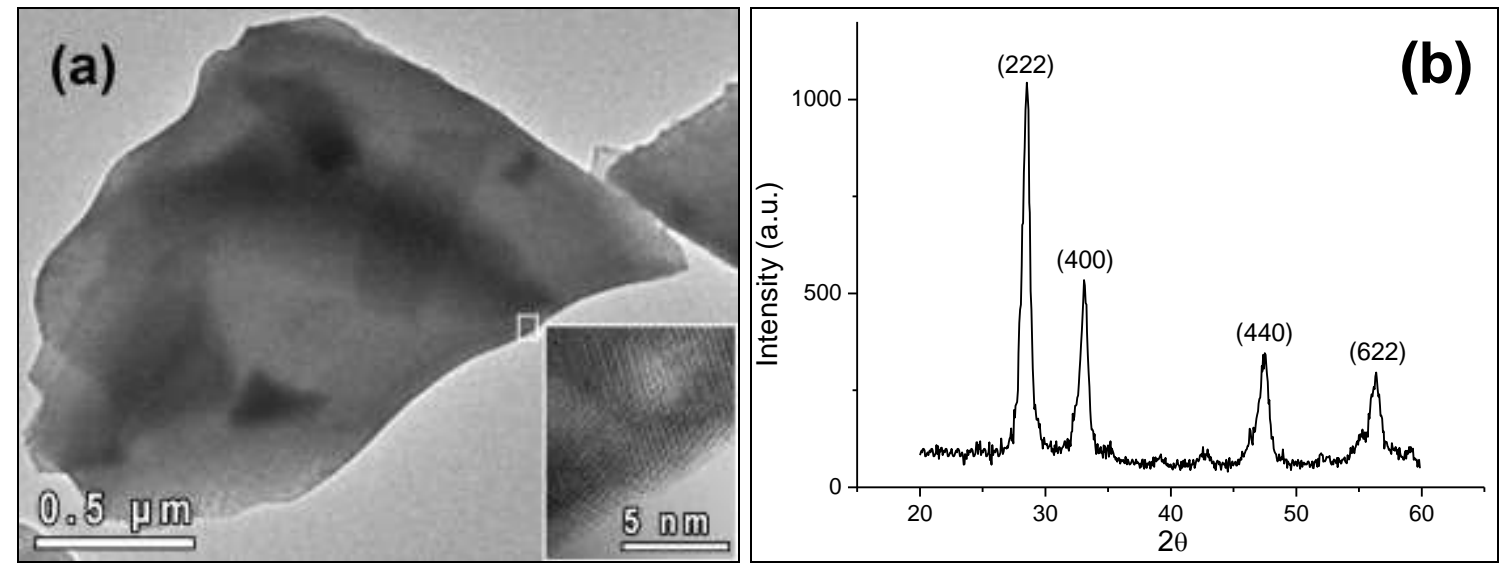

Fig. 3. 


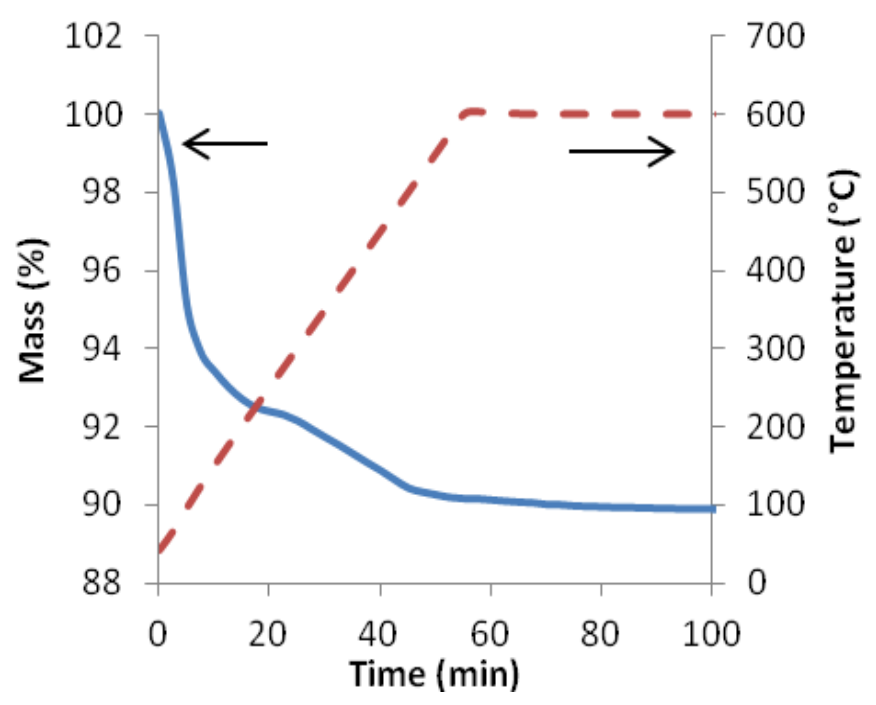

Fig. 4.
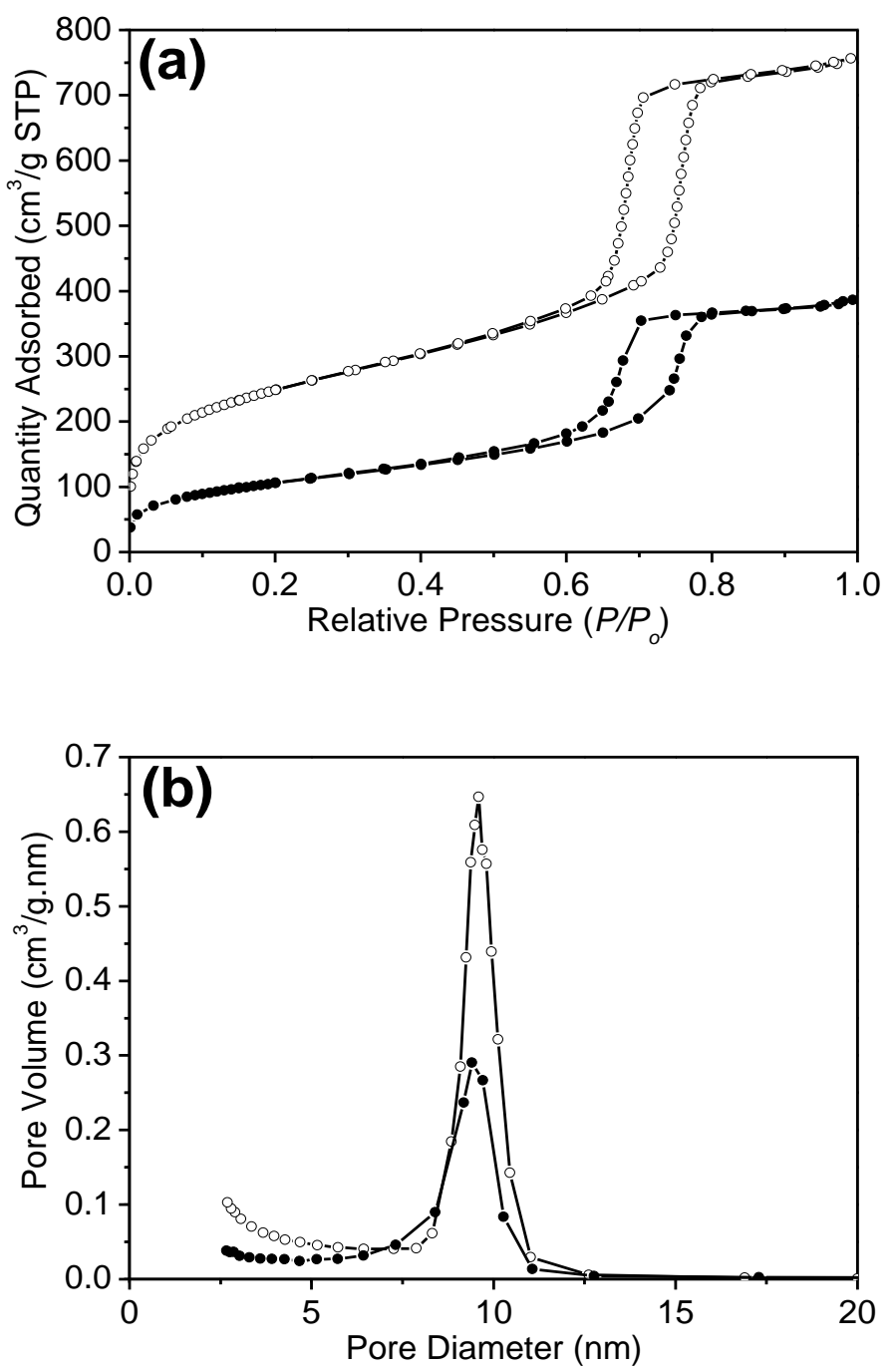
Fig. 5.
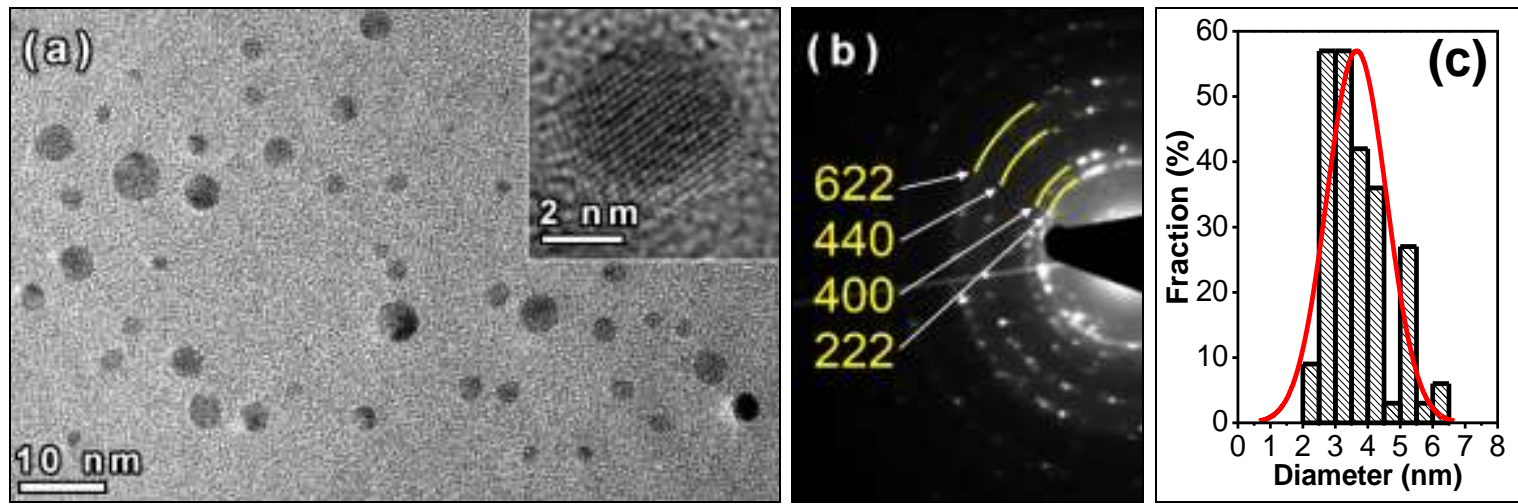

Fig. 6.

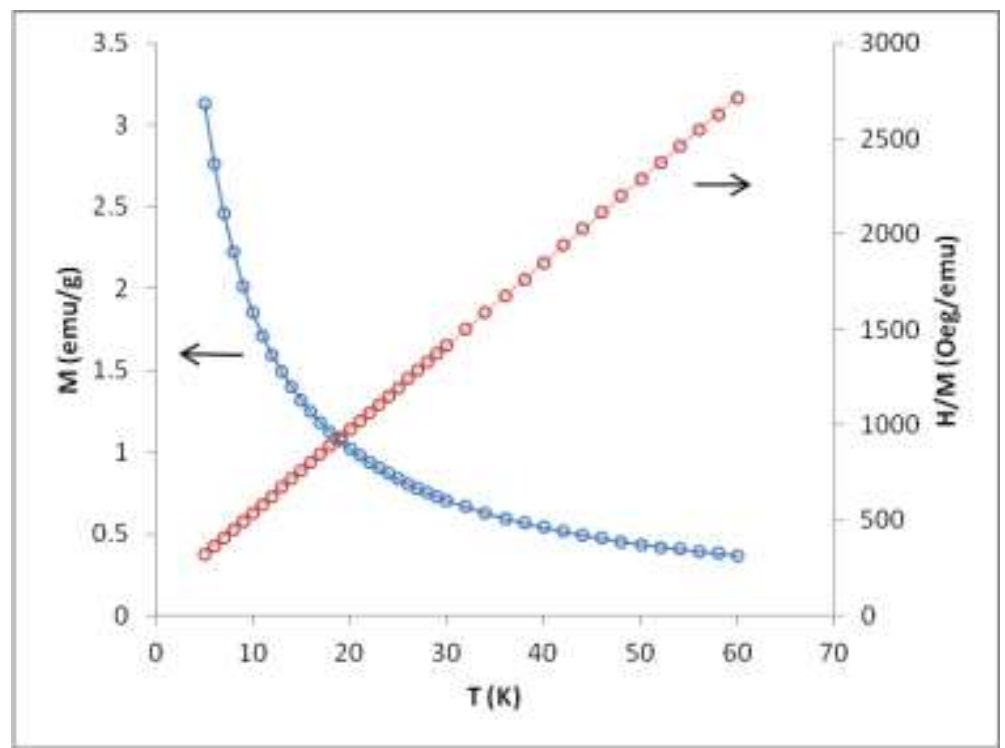

Fig. 7. 


\section{Supporting information for:}

\section{Growth of $\mathrm{Gd}_{2} \mathrm{O}_{3}$ nanoparticles inside mesoporous silica frameworks}

Mohamed Ali Ballem ${ }^{\mathrm{a}}$, Fredrik Söderlind ${ }^{\mathrm{a}, *}$, Per Nordblad $^{\mathrm{b}}$, Per-Olov Käll ${ }^{\mathrm{c}}$, and Magnus Odén ${ }^{\mathrm{a}}$

${ }^{a}$ Division of Nanostructured Materials, Department of Physics, Chemistry and Biology, Linköping University, 58183 Linköping, Sweden

${ }^{b}$ Department of Engineering Sciences, Uppsala University, Box 534, SE-751 21 Uppsala, Sweden

${ }^{c}$ Division of Chemistry, Department of Physics, Chemistry and Biology, Linköping University, 58183 Linköping, Sweden

Figure S1. (a) EDS spectrum of SBA-15 silica template impregnated with $\mathrm{Gd}_{2} \mathrm{O}_{3}$ nanoparticles, (b) EDS spectrum of $\mathrm{Gd}_{2} \mathrm{O}_{3}$ nanoparticles after dissolution of the SBA-15 template. 

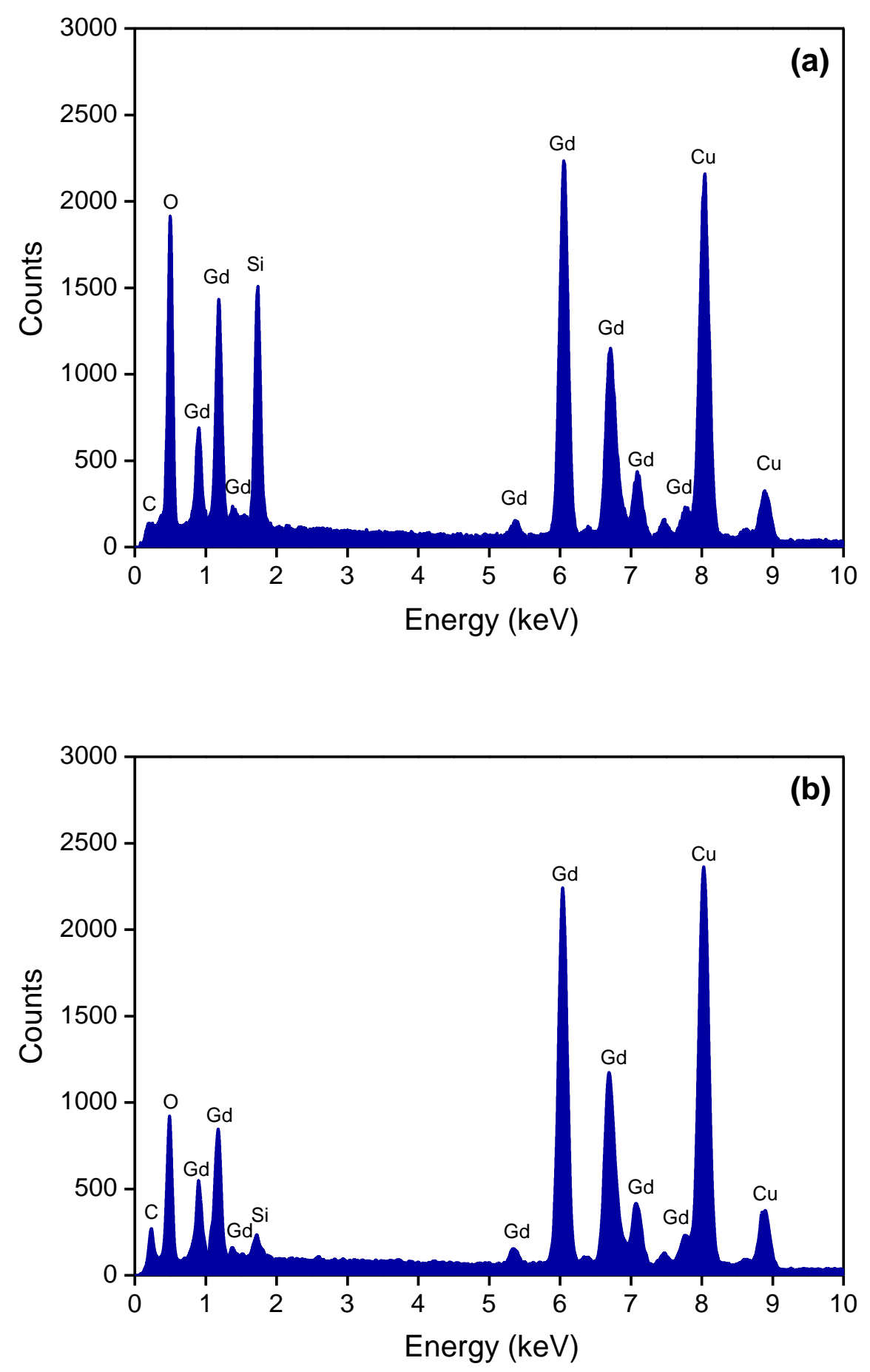

Figure S1. (a) EDS spectrum of SBA-15 silica template impregnated with $\mathrm{Gd}_{2} \mathrm{O}_{3}$ nanoparticles, (b) EDS spectrum of $\mathrm{Gd}_{2} \mathrm{O}_{3}$ nanoparticles after dissolution of the SBA-15 template. 